\title{
Interventions to Improve Adherence to Cardiovascular Medication: What About Gender Differences? A Systematic Literature Review
}

This article was published in the following Dove Press journal: Patient Preference and Adherence

\author{
Marcia Vervloet ${ }^{\prime}$ \\ Joke C Korevaar (D) \\ Chantal J Leemrijse (ID) \\ John Paget' \\ Leah L Zullig ${ }^{2,3}$ \\ Liset van Dijk (1D ${ }^{1,4}$
}

'Nivel, Netherlands Institute for Health Services Research, Utrecht, the Netherlands; ${ }^{2}$ Department of Population Health Sciences, Duke University School of Medicine, Durham, North Carolina, USA; ${ }^{3}$ Center of Innovation to Accelerate Discovery and Practice Transformation (ADAPT), Durham Veterans Affairs Health Care System, Durham, North Carolina, USA; ${ }^{4}$ University of Groningen, Groningen Research Institute of Pharmacy, Department of Pharmacotherapy, -Epidemiology and -Economics, Groningen, the Netherlands
Correspondence: Marcia Vervloet Nivel, Netherlands Institute for Health Services Research, P.O. Box 1568 , Utrecht 3500 BN, the Netherlands Tel +3I 302729713

Email M.Vervloet@nivel.nl
Background: Compared to men, women have lower treatment rates for cardiovascular disease (CVD), are at higher risk for medication non-adherence and have different reasons for being non-adherent. The aim of this study was to synthesize and evaluate gender-specific adherence-promoting interventions for cardiovascular medication and gender-specific effects of gender-neutral interventions.

Methods: A systematic literature search was performed in PubMed, Embase, PsycINFO, CINAHL and Cochrane Library from January 2007 to October 2019. Intervention studies (with control group) aimed at improving cardiovascular medication adherence with minimally 14 weeks follow-up were included. Two reviewers independently screened titles and abstracts. Full text was obtained for selected abstracts and screened for final inclusion. Data extraction included gender-specific targeting or analysis.

Results: The search identified 6502 citations. After screening title and abstract, full text was obtained from 127 potentially eligible articles. Ultimately, 11 articles were included that analyzed gender differences in gender-neutral interventions. Two reported a gender-specific intervention effect. Using an electronic reminder device, one study increased statin adherence in women. The other found a larger increase in adherence to CVD medication following telephone counseling for men than women. Nine studies did not identify a gender-specific effect.

Conclusion: Despite differences in levels of and reasons for non-adherence, most studies addressing adherence did not analyze potential differences in effect by gender. Moreover, none of the identified studies used gender-specific adherence promoting interventions. Increasing awareness about gender differences in adherence might lead to better tailoring of interventions to gender-specific needs and better results in improving adherence.

Keywords: gender, medication adherence, cardiovascular medication, intervention, systematic review

\section{Introduction}

Among both men and women cardiovascular diseases (CVD) are one of the leading causes of burden of disease and mortality worldwide. ${ }^{1}$ Despite public health and medication interventions to reduce the risk for a cardiovascular event through prevention, screening, and early treatment, risk reduction has been modest at the population level. ${ }^{2,3}$ Moreover, cardiovascular risk reduction has been more effective among men than women. ${ }^{4,5}$ There are several reasons for this gender disparity, including lower treatment rates for cardiovascular medication in women, ${ }^{6,7}$ as healthcare providers perceive women to have lower cardiovascular $\operatorname{risk}^{8}$ and 
differences in the type of prescribed medication and in comorbidities. $^{6,9,10}$ Gender is also associated with medication adherence. ${ }^{4,11,12}$ Adherence is defined as the extent to which a person's medication taking behavior corresponds with agreed recommendations from a healthcare provider. There are three stages of medication adherence: initiation, implementation and discontinuation. ${ }^{13}$ Initiation refers to when the patient starts the therapy, when the first dosage is actually taken. Implementation refers to the extent to which a patient's actual dosing corresponds to the prescribed dosing regimen, from initiation until the last dose. Discontinuation is when the patient stops taking the prescribed medication. Persistence is the length of time between the first and last dose. These stages represent different types of medication taking behavior. Mechanisms underlying this behavior may differ between men and women.,12 Evidence of gender differences already exists for other health behaviors, such as seeking health information, completion of health screenings, engagement in social and physical activities, and alcohol consumption patterns. ${ }^{14,15}$

In the case of cardiovascular medication adherence, there are inconsistent results regarding gender differences. A meta-analysis by Lewey et al (2013) showed that for statin use women are more at risk for non-adherence; compared to men, women had $10 \%$ greater odds of nonadherence. ${ }^{16}$ This was confirmed by two recent systematic literature reviews both showing that female sex, amongst other factors, contributed to non-adherence to statins. ${ }^{17,18}$ Yet, other studies did not find differences between men and women for antihypertensive medication. ${ }^{19,20}$ Even when adherence levels between men and women are comparable, reasons associated with non-adherence may differ between men and women. ${ }^{12,20}$ For example, gender-specific reasons for adherence to statins include a lower awareness of CVD risk and a higher statin intolerance in women compared to men. Moreover, women have been found to have a more negative perception of medicines than men. ${ }^{4}$ This negative perception can be the result of women having more frequent and stronger adverse effects. ${ }^{11}$ Adverse effects in women are associated with discontinuation of statin treatment ${ }^{21}$ and lower lipid control. ${ }^{22}$ In addition, healthcare providers less often were warned for their risk. Thus, given the different levels of adherence and, more importantly, the differences in reasons between men and women not to adhere to cardiovascular medication, attempts to improve adherence might need to pay attention to gender-specific causes of non-adherence in all stages of medication intake behavior in order to be successful. To our knowledge, no review has been conducted that systematically studied interventions using gender-specific approaches to improve adherence to cardiovascular medication. Therefore, the aim of our study is to synthesize and evaluate gender-specific approaches in adherence-promoting interventions for cardiovascular medication as well as differences in the effectiveness of gender-neutral interventions for men and women.

\section{Materials and Methods}

This systematic review was conducted following the guidelines of PRISMA (Preferred Reporting Items for Systematic reviews and Meta-analyses) ${ }^{23}$ and EMERGE (ESPACOMP Medication Adherence Reporting Guideline). ${ }^{24}$

\section{Search Strategy}

The search strategy was defined after extensive discussions in the research group and consultation of a general practitioner with special interest in cardiovascular disease and an experienced medical librarian. Next, a comprehensive search was performed in collaboration with the medical librarian in the bibliographic databases PubMed, Embase, PsycINFO (via Ebsco), CINAHL (via Ebsco) and the Cochrane Library (via Wiley) from 1 January 2007 to December 2017, an update was performed at 6 October 2019. Gender has only recently become a known determinant of medication adherence. As a result, we highlighted literature from 2007 to 2019. To identify all relevant publications, search terms included controlled terms from MeSH in PubMed, EMtree in Embase, CINAHL Headings in CINAHL, Thesaurus terms in PsycINFO. We used only free-text terms for The Cochrane Library. The following terms were used (including synonyms and closely related words) as index terms or free-text words ("cardiovascular medication" OR 'antihypertensive agents' OR "anticoagulants' OR beta-blocking agents" OR "lipid lowering medication") AND "compliance" AND "sex differences" AND ("intervention" OR "clinical trials"). The search was performed without language restriction. The full search strategies and synonyms used for all databases can be found in the Supplementary Materials.

\section{Inclusion Criteria}

A study was included in this review if it met the following inclusion criteria: 
1. The study described an intervention aimed at improving adherence to cardiovascular medication (antihypertensive medication, lipid lowering medication, anticoagulants);

2. Medication adherence was one of the outcome measures;

3. The study design was a randomized controlled trial (RCT), a controlled clinical trial (CCT), or an intervention study with control group;

4. The control group did not receive any type of intervention (usual care);

5. The follow-up period was minimally 14 weeks to be able to see sustainable effects;

6. The study was conducted in Europe, USA, Canada, Australia or New Zealand to include studies from countries with comparable levels of development of healthcare;

7. The study was published in English or Dutch (authors' native language);

8. The study used a gender-specific approach or the gender-specific effects of the intervention were analyzed, by means of subgroup analysis or with an interaction term.

\section{Review Procedures}

Endnote X7.4 was used to manage all citations. Two pairs of reviewers (MV/LvD, JK/CL) independently screened the titles of the citations identified by the electronic database searches. Next, the abstracts of the selected titles were independently screened by two reviewers (MV and LvD). We obtained full text for studies that had insufficient information from the abstract to determine eligibility and for potentially eligible studies. The inter-rater agreement (Cohen's Kappa) between MV and LvD for the screening of abstracts was $82.6 \%$, indicating a high agreement according to Landis \& Koch (1977). Disagreements between reviewers were discussed until consensus was reached. Full text articles were reviewed independently by MV, JP and LvD to identify gender-specific intervention effects.

\section{Data Extraction}

The following information was extracted from the included studies: first author, publication year, country, study design, study population, type, setting and aim of intervention as well as the content of the intervention. Furthermore, adherence outcomes and type of adherence measurement were extracted as well as the overall intervention effects and gender-specific intervention effects.

\section{Quality Assessment}

Following the Cochrane Handbook of Systematic Reviews of Interventions, version 5.1.0 (http://handbook-5-1. cochrane.org/), risk of bias of the individual studies was assessed independently by two reviewers (MV and LvD) for six domains. These domains were: selection bias (bias due to inadequate random sequence generation or concealment of allocation), performance bias (bias due to knowledge of allocation of personnel and participants), detection bias (bias due to knowledge of allocation of the outcome assessors), attrition bias (bias due to amount, nature or handling of incomplete outcome data), reporting bias (bias due to selective outcome reporting) and other bias (bias due to other problems not stated above). For each type of bias, the study was assessed as having low risk, unclear risk or high risk of bias.

\section{Results}

A total of 6508 unique citations were identified through the electronic database searches. After screening title and abstract, 127 potentially eligible articles remained. After reviewing full texts of these selected abstracts, 27 articles were excluded for not meeting the first seven inclusion criteria. In addition, we excluded one study had a study population that comprised $98 \%$ of men. Regarding the last inclusion criterion, none of the remaining 99 articles described a gender-specific intervention (ie, an intervention that targeted potentially different needs of men and women). Eleven studies analyzed gender-specific differences in intervention effects and were included in this review (Figure 1).

\section{Description of the Studies}

Eight of the eleven included studies described an overall effective intervention, which we defined as an intervention that demonstrated a significant difference in adherence to cardiovascular medication in favor of the intervention group compared to the control group. ${ }^{25-32}$ Three studies found no overall effect on adherence. ${ }^{33-35}$ Two studies found a significant gender-specific intervention effect, ${ }^{31,34}$ whilst the other nine studies found no gender-specific effects, ie, the intervention was equally effective (or ineffective) for men and women. Four studies were multicomponent studies versus eleven single component studies (see Table 1). 


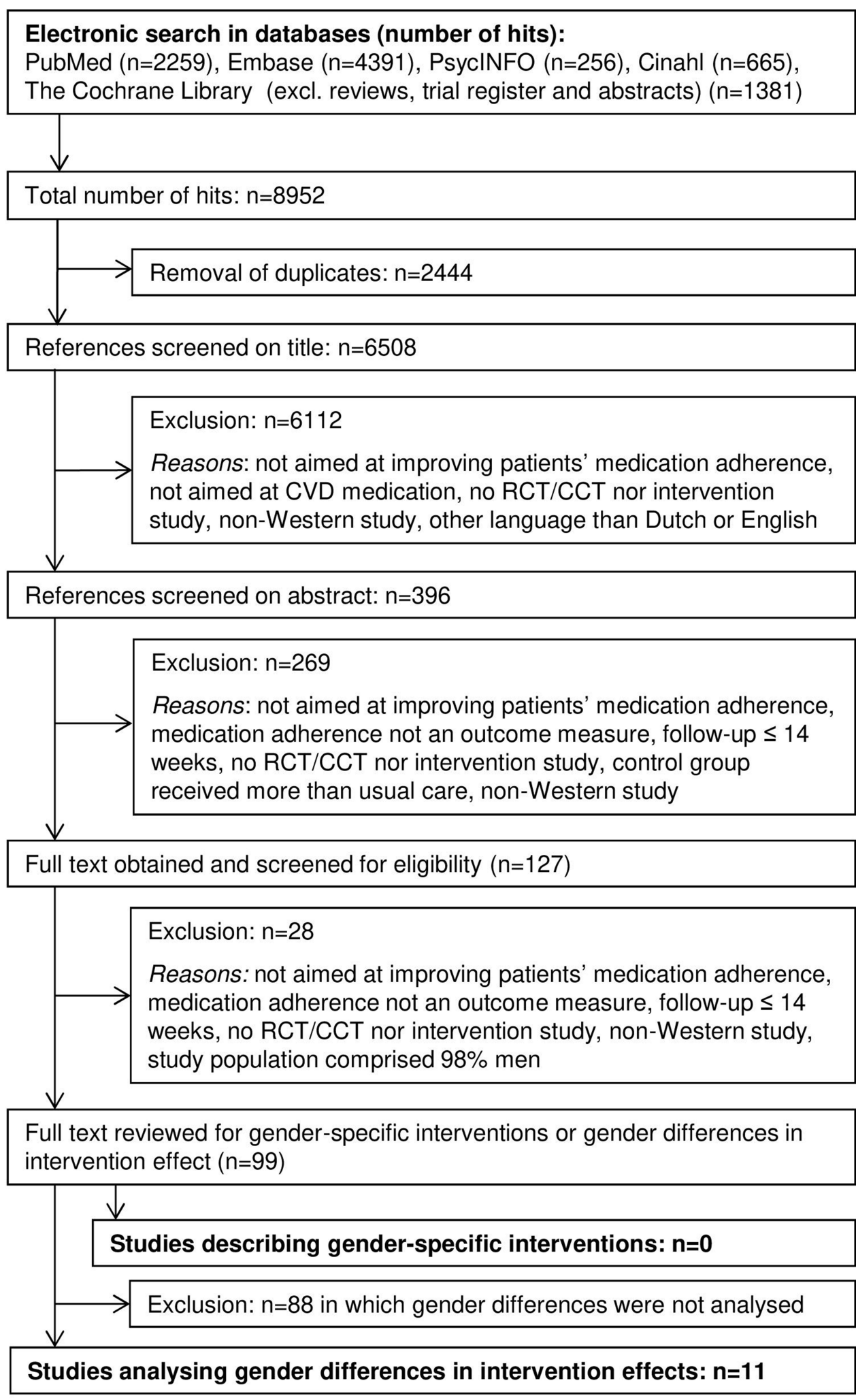

Figure I Flowchart of study inclusion.

Abbreviations: CVD, cardiovascular disease; RCT, randomized controlled trial; $C C T$, clinical controlled trial. 
Table I Characteristics of Studies Describing Interventions for Which Subgroup Analyses are Performed to Investigate Gender Differences in Intervention Effects

\begin{tabular}{|c|c|c|c|c|}
\hline $\begin{array}{l}\text { Author, } \\
\text { Publication } \\
\text { Year, Country }\end{array}$ & $\begin{array}{l}\text { Study } \\
\text { Design }\end{array}$ & Study Population & $\begin{array}{l}\text { Type, Setting and Aim } \\
\text { of Intervention }\end{array}$ & Intervention Description \\
\hline \multicolumn{5}{|c|}{ Interventions WITH gender-specific Intervention Effect } \\
\hline $\begin{array}{l}\text { Choudry, 2018, } \\
\text { USA }^{31}\end{array}$ & $\begin{array}{l}\text { Cluster } \\
\text { RCT }\end{array}$ & $\begin{array}{l}4078 \text { patients with suboptimal control of } \\
\text { hyperlipidemia, hypertension, or diabetes, and } \\
\text { being non-adherent to prescribed treatment. } \\
\text { Intervention group: } \mathrm{n}=2038(+\mathrm{n}=924) \\
\text { Control group: } \mathrm{n}=2040 \text { ( } \mathrm{n}=917)\end{array}$ & $\begin{array}{l}\text { Type: multicomponent; } \\
\text { Telephone counseling, text } \\
\text { messaging and pillboxes, } \\
\text { mailed progress reports } \\
\text { Setting: Clinical pharmacy in } \\
\text { primary care } \\
\text { Aim: improve medication } \\
\text { adherence among patients } \\
\text { with hypertension, } \\
\text { hyperlipidemia, or diabetes }\end{array}$ & $\begin{array}{l}\text { A trained clinical pharmacist conducted an } \\
\text { individually tailored telephone consultation, } \\
\text { during which potential adherence barriers or } \\
\text { other factors that may contribute to poor } \\
\text { disease control were discussed as well as the } \\
\text { patient's readiness to modify behaviors. Patient } \\
\text { and pharmacist together composed a plan to } \\
\text { improve adherence and disease control, using. } \\
\text { strategies that included text messages, pillboxes, } \\
\text { and mailed progress reports. }\end{array}$ \\
\hline $\begin{array}{l}\text { Kooy, 2013, The } \\
\text { Netherlands }{ }^{34}\end{array}$ & RCT & $\begin{array}{l}381 \text { patients who had started statins at least one } \\
\text { year prior to inclusion and were non-adherent } \\
\text { (refill rate between } 50-80 \%) \text { in preceding year. } \\
\text { Intervention group } 1: n=130(+n=69) \\
\text { Intervention group } 2: n=123(+n=70) \\
\text { Control group: } n=128(+n=74)\end{array}$ & $\begin{array}{l}\text { Type: multicomponent; } \\
\text { electronic reminder device } \\
\text { (ERD) with or without } \\
\text { counseling } \\
\text { Setting: Community } \\
\text { pharmacy } \\
\text { Aim: improve adherence } \\
\text { and persistence to statin } \\
\text { treatment }\end{array}$ & $\begin{array}{l}\text { Two intervention groups: } \\
\text { I) ERD and non-adherence counseling in which } \\
\text { the pharmacist provided feedback on patients' } \\
\text { previous drug dispensing data, discussed reasons } \\
\text { for non-adherence, provided information about } \\
\text { the benefits of statin use. } \\
\text { 2) ERD only. Patients received the ERD by mail } \\
\text { with user instructions. }\end{array}$ \\
\hline \multicolumn{5}{|c|}{ Interventions WITHOUT gender-specific intervention effect } \\
\hline $\begin{array}{l}\text { Derose, } 2013 \\
\text { USA }^{25}\end{array}$ & RCT & $\begin{array}{l}5,216 \text { new statin users } \\
\text { Intervention group: } \mathrm{n}=2,606(+51,0 \%) \\
\text { Control group: } \mathrm{n}=2,610(+50,1 \%)\end{array}$ & $\begin{array}{l}\text { Type: single component; } \\
\text { automated telephone call } \\
\text { and messaging } \\
\text { Setting: direct messaging to } \\
\text { members of Kaiser } \\
\text { Permanente Southern } \\
\text { California (health plan) } \\
\text { Aim: decrease primary } \\
\text { nonadherence to statins }\end{array}$ & $\begin{array}{l}\text { Patients received an automated telephone call I } \\
\text { to } 2 \text { weeks after the prescription date. A } \\
\text { personalized message provided them with } \\
\text { information on the benefits of the therapy and } \\
\text { encouraged them to fill the prescription. } \\
\text { Patients who still did not fill their prescription a } \\
\text { week after the telephone call were sent a letter } \\
\text { signed by their prescriber. }\end{array}$ \\
\hline $\begin{array}{l}\text { Eussen, } 2010 \\
\text { The Netherlands } \\
26\end{array}$ & RCT & $\begin{array}{l}899 \text { new statins users. } \\
\text { Intervention group: } n=439(+n=232) \\
\text { Control group: } n=460(+n=230)\end{array}$ & $\begin{array}{l}\text { Type: single component; } \\
\text { counseling } \\
\text { Setting: community } \\
\text { pharmacy } \\
\text { Aim: improve adherence to } \\
\text { statin therapy, especially in } \\
\text { the first months after } \\
\text { initiation. }\end{array}$ & $\begin{array}{l}\text { Five individual counseling visits in the pharmacy, } \\
\text { at first dispense, second dispense and dispenses } \\
\text { at } 3,6 \text {, and } 12 \text { months. Counseling at first } \\
\text { dispense included education about the } \\
\text { medication and the importance of adherence. } \\
\text { Patients were given a written summary of the } \\
\text { verbal information. At second dispense, patients } \\
\text { were asked about their experience (incl. } \\
\text { potential barriers to adherence). The association } \\
\text { between adherence and lipid levels was } \\
\text { discussed to encourage patients to adhere. }\end{array}$ \\
\hline $\begin{array}{l}\text { Patel, } 2015 \\
\text { Australia } 27\end{array}$ & RCT & $\begin{array}{l}623 \text { patients with an established CVD or an } \\
\text { estimated five-year CVD risk of } \geq 15 \% \text { with } \\
\text { indications for antiplatelet, statin and } \geq 2 \text { blood } \\
\text { pressure lowering drugs. } \\
\text { Intervention group: } n=31 \text { I }(\text { }(+n=1 \mid 4) \\
\text { Control group: } n=312(+n=\mid 17)\end{array}$ & $\begin{array}{l}\text { Type: single component; } \\
\text { polypill-based strategy } \\
\text { Setting: general practice } \\
\text { Aim: improve adherence to } \\
\text { CVD medication }\end{array}$ & $\begin{array}{l}\text { Patients used a polypill (fixed-dose combination) } \\
\text { containing aspirin } 75 \mathrm{mg} \text {, simvastatin } 40 \mathrm{mg} \text {, } \\
\text { lisinopril } 10 \mathrm{mg} \text { and either atenolol } 50 \mathrm{mg} \\
\text { (version I) or hydrochlorothiazide } 12.5 \mathrm{mg} \\
\text { (version 2). The control group used separate } \\
\text { medications and doses as prescribed by their } \\
\text { doctor. }\end{array}$ \\
\hline
\end{tabular}

(Continued) 
Table I (Continued).

\begin{tabular}{|c|c|c|c|c|}
\hline $\begin{array}{l}\text { Schulz, } 2019 \\
\text { Germany }\end{array}$ & $\mathrm{RCT}$ & $\begin{array}{l}237 \text { patients of } \geq 60 \text { years with chronic heart } \\
\text { failure (CHF), treated with a diuretic, } \\
\text { hospitalized for } \mathrm{HF} \text { within the last } 12 \text { months or } \\
\text { with increased B-type natriuretic peptide or } \mathrm{N} \text { - } \\
\text { terminal pro-B-type natriuretic peptide } \\
\text { concentrations. } \\
\text { Intervention group: } \mathrm{n}=110(+\mathrm{n}=42) \\
\text { Control group: } \mathrm{n}=127(+\mathrm{n}=49)\end{array}$ & $\begin{array}{l}\text { Type: multicomponent; } \\
\text { medication review, (bi-) } \\
\text { weekly dosing aids and } \\
\text { counseling } \\
\text { Setting: community } \\
\text { pharmacy } \\
\text { Aim: improve adherence for } \\
\text { three heart failure } \\
\text { medication classes in elderly } \\
\text { patients with CHF. }\end{array}$ & $\begin{array}{l}\text { A medication review was conducted to generate } \\
\text { a medication plan. Patients received a weekly } \\
\text { dosing aid and printout of the plan. (Bi-)weekly } \\
\text { pharmacy visits thereafter during which the plan } \\
\text { was updated (if necessary), dosing aids were } \\
\text { supplied, medication counselling was given, and } \\
\text { the physician was contacted (if necessary). }\end{array}$ \\
\hline $\begin{array}{l}\text { Selak, } 2014 \\
\text { New Zealand }{ }^{28}\end{array}$ & $\mathrm{RCT}$ & $\begin{array}{l}513 \text { adults with an established CVD or an } \\
\text { estimated five-year CVD risk of } \geq 15 \% \\
\text { recommended for treatment with antiplatelet, } \\
\text { statin, and } \geq 2 \text { blood pressure lowering drugs. } \\
\text { Intervention group: } n=256(+n=99) \\
\text { Control group: } n=257(+n=88)\end{array}$ & $\begin{array}{l}\text { Type: single component; } \\
\text { polypill-based strategy } \\
\text { Setting: general practice } \\
\text { Aim: improve adherence to } \\
\text { CVD medication }\end{array}$ & $\begin{array}{l}\text { Patients used a polypill (fixed-dose combination) } \\
\text { containing aspirin } 75 \mathrm{mg} \text {, simvastatin } 40 \mathrm{mg} \text {, } \\
\text { lisinopril } 10 \mathrm{mg} \text { and either atenolol } 50 \mathrm{mg} \\
\text { (version I) or hydrochlorothiazide } 12.5 \mathrm{mg} \\
\text { (version 2). The control group used separate } \\
\text { medications and doses as prescribed by their } \\
\text { doctor. }\end{array}$ \\
\hline $\begin{array}{l}\text { Vollmer, } 2014 \\
\text { USA }^{29}\end{array}$ & $\begin{array}{l}\text { Pragmatic } \\
\text { clinical } \\
\text { trial }\end{array}$ & $\begin{array}{l}21,752 \text { participants, } \geq 40 \text { years, with diabetes } \\
\text { mellitus and/or CVD who were suboptimally } \\
\text { adherent (<90\%) to a statin or ACEI and ARBs } \\
\text { and (over)due for a refill. } \\
\text { Intervention group I: } n=7,247 \text { ( }+46.5 \%) \\
\text { Intervention group } 2: n=7,250(+47.1 \%) \\
\text { Control group: } n=7,255 \text { ( }+47.3 \%)\end{array}$ & $\begin{array}{l}\text { Type: single component; } \\
\text { automated reminder } \\
\text { Setting: direct } \\
\text { communication to patients } \\
\text { Aim: improve adherence to } \\
\text { statins, or ACEl and ARBs. }\end{array}$ & $\begin{array}{l}\text { Two intervention groups using interactive voice } \\
\text { recognition (IVR) calls: } \\
\text { (I) IVR group received automated phone calls } \\
\text { when they were (over)due for a refill. } \\
\text { (2) IVR+ group received the same phone calls, } \\
\text { plus a personalized reminder letter, a live } \\
\text { outreach call, EMR-based feedback to their } \\
\text { primary care provider, and additional mailed } \\
\text { materials. }\end{array}$ \\
\hline $\begin{array}{l}\text { Wald, } 2014 \\
\text { UK }{ }^{30}\end{array}$ & $\mathrm{RCT}$ & $\begin{array}{l}30 \text { I patients taking blood pressure and/or lipid- } \\
\text { lowering medications. } \\
\text { Intervention group: } \mathrm{n}=150(q \mathrm{n}=68) \\
\text { Control group: } \mathrm{n}=151(+\mathrm{n}=70)\end{array}$ & $\begin{array}{l}\text { Type: single component; } \\
\text { text messaging } \\
\text { Setting: direct } \\
\text { communication to patients } \\
\text { Aim: improve adherence to } \\
\text { blood pressure and/or lipid- } \\
\text { lowering treatment }\end{array}$ & $\begin{array}{l}\text { Daily text messages for } 2 \text { weeks, on alternate } \\
\text { days for } 2 \text { weeks and once weekly for } 22 \text { weeks. } \\
\text { Patients were asked to respond whether they } \\
\text { had taken their medication, whether the text } \\
\text { reminded them, and the reason if they had not } \\
\text { taken their medication. }\end{array}$ \\
\hline \multicolumn{5}{|c|}{ Ineffective Interventions (neither a gender-neutral nor a gender-specific intervention effect) } \\
\hline $\begin{array}{l}\text { Blackburn, } 2016 \\
\text { Canada } 35\end{array}$ & $\begin{array}{l}\text { Cluster } \\
\text { RCT }\end{array}$ & $\begin{array}{l}\text { I,906 new statins users. } \\
\text { Intervention group: } n=907(+n=447) \\
\text { Control group: } n=999(+n=431)\end{array}$ & $\begin{array}{l}\text { Type: single component; } \\
\text { counseling } \\
\text { Setting: community } \\
\text { pharmacy } \\
\text { Aim: prevent nonadherence } \\
\text { during the first year of } \\
\text { statin use }\end{array}$ & $\begin{array}{l}\text { Two brief screening questions: } \\
\text { I) "How long have you been taking this } \\
\text { medication?" } \\
\text { 2) (example) "Are you having any difficulties or } \\
\text { concerns with this new medication?" } \\
\text { Pharmacists were challenged to personalize the } \\
\text { second screening question. }\end{array}$ \\
\hline $\begin{array}{l}\text { Volpp, } 2017 \\
\text { USA }^{33}\end{array}$ & $\mathrm{RCT}$ & $\begin{array}{l}\text { I,503 patients surviving acute myocardial } \\
\text { Infarction (AMI), were prescribed at least } 2 \text { of } \\
\text { the } 4 \text { medications (statin, aspirin, } \beta \text {-blocker, } \\
\text { antiplatelet agent). } \\
\text { Intervention group: } n=1000(q n=343) \\
\text { Control group: } n=503(+n=190)\end{array}$ & $\begin{array}{l}\text { Type: multicomponent; } \\
\text { electronic reminder, lottery } \\
\text { incentive and social support } \\
\text { Setting: direct } \\
\text { communication to patients } \\
\text { Aim: improve adherence to } \\
\text { CVD medication in patients } \\
\text { surviving AMI }\end{array}$ & $\begin{array}{l}\text { Use of electronic pill bottles, combined with } \\
\text { daily incentives and social support (enlisting a } \\
\text { friend or family member who would be notified } \\
\text { if medication was missed, access to social work } \\
\text { resources, a staff engagement advisor to provide } \\
\text { close monitoring, feedback, and adherence } \\
\text { reinforcement). }\end{array}$ \\
\hline
\end{tabular}

Abbreviations: RCT, randomized controlled trial; CVD, cardiovascular disease; + , female. 


\section{Type and Setting of Intervention}

Five studies described pharmacist-led interventions in which counseling was one of the components used to improve adherence, ${ }^{26,31,32,34,35}$ and in four this was the main component of the intervention. ${ }^{26,31,32,35}$ In three of these studies, pharmacists counseled patients during pharmacy visits, ${ }^{26,32,35}$ two studies used telephone counseling. ${ }^{31,34}$ Two studies were performed in a general practice. ${ }^{27,28}$ Both employed a poly-pill strategy for CVD preventive medication (combination of statin, antihypertensive and antiplatelet medication). In four studies the intervention was directly aimed at patients without interference of a healthcare provider. ${ }^{25,29,30,33}$ All four studies used an automated method to increase adherence, either via automated telephone calls reminding patients to refill their prescriptions, ${ }^{25,29}$ or text messages ${ }^{30}$ and electronic reminders ${ }^{33}$ to remind patients of the medication intake moment. The latter study also added lottery incentives and social support as components to increase adherence.

\section{Stages of Adherence}

Adherence in the implementation stage was most frequently investigated: in eight studies, including the two studies in which a gender-specific effect was found ${ }^{27-34}$ (see also Table 2). Most often this was studied using pharmacy refill data, claims data or prescription data which allows monitoring patients' medication use over a longer period (necessary for studying implementation). One study specifically investigated the initiation stage, by aiming their intervention at decreasing the number of patients not starting their statin treatment at all, ${ }^{25}$ whereas two other studies focused on new users of statins and aimed to increase adherence in the first months up to a year after initiation. ${ }^{26,35}$ Four studies additionally investigated early discontinuation of the treatment (non-persistence). ${ }^{26,30,34,35}$

\section{Targeting Patients}

Although none of the studies made a distinction in gender in targeting patients for their intervention, some of them did target a specific patient group. Three interventions targeted patients who were non-adherent to the study medication in the preceding year, including the two interventions finding a gender-specific effect. ${ }^{29,31,34}$ Two studies specifically targeted patients with an established CVD or estimated 5-year CVD risk of at least $15 \% .{ }^{27,28}$ One study targeted survivors of an acute myocardial infarction for increasing adherence to CVD medication, ${ }^{33}$ and another targeted elderly patients with chronic heart failure. ${ }^{32}$
Table 1 describes the characteristics of the eleven intervention studies in detail. Table 2 describes the methods used to assess adherence and the intervention effects, both the overall results and the gender-specific results of the eleven included studies.

\section{Studies Finding a Gender-Specific Effect}

Two studies found a gender-specific effect. Both were multicomponent pharmacist-led interventions, aimed at non-adherent patients (patients who collected less than $80 \%$ of their medication at the pharmacy in the year before the study). Kooy et al (2013) investigated the effectiveness of an electronic reminder device (ERD) with or without counseling by the community pharmacist to improve adherence to and persistence with statin therapy. ${ }^{34}$ They composed three groups: (1) patients who used the ERD and received 10-minute counseling; (2) patients who only used the ERD; and (3) patients who received usual care. They found no overall differences in refill adherence or persistence between the three groups. However, subgroup analysis revealed a significant effect of the ERD only on adherence of women using statins for secondary prevention. The odds of women in the intervention group being adherent were 8.26 times higher than the odds of women in the control group. No such effect was apparent for men.

Choudry et al (2018) investigated whether an intervention comprising a telephone consultation in which experienced barriers to adherence were identified, patients' motivation to change their (adherence) behavior was assessed, and a personal action plan was drafted, improved adherence to statins, antihypertensives or oral glucoselowering medication. ${ }^{31}$ Compared to usual care, the intervention group showed a small but significant increase of $4.7 \%$ in overall medication adherence (average of averages for the three medication groups together). Evaluating the medication subgroups, significant differences were found for statins (increase of $4.5 \%$ ) and antihypertensives (increase of 8.4\%) but not for oral glucose-lowering medication (decrease of $1.5 \%$ ). Subgroup analysis showed that the intervention effect was significantly larger in men (increase in overall adherence of 6.7\%) than in women (increase of 1.2\%).

\section{Studies Finding No Gender-Specific Effects}

Of the nine studies finding no gender-specific effects, two did not find any effect. In one study, a medication 


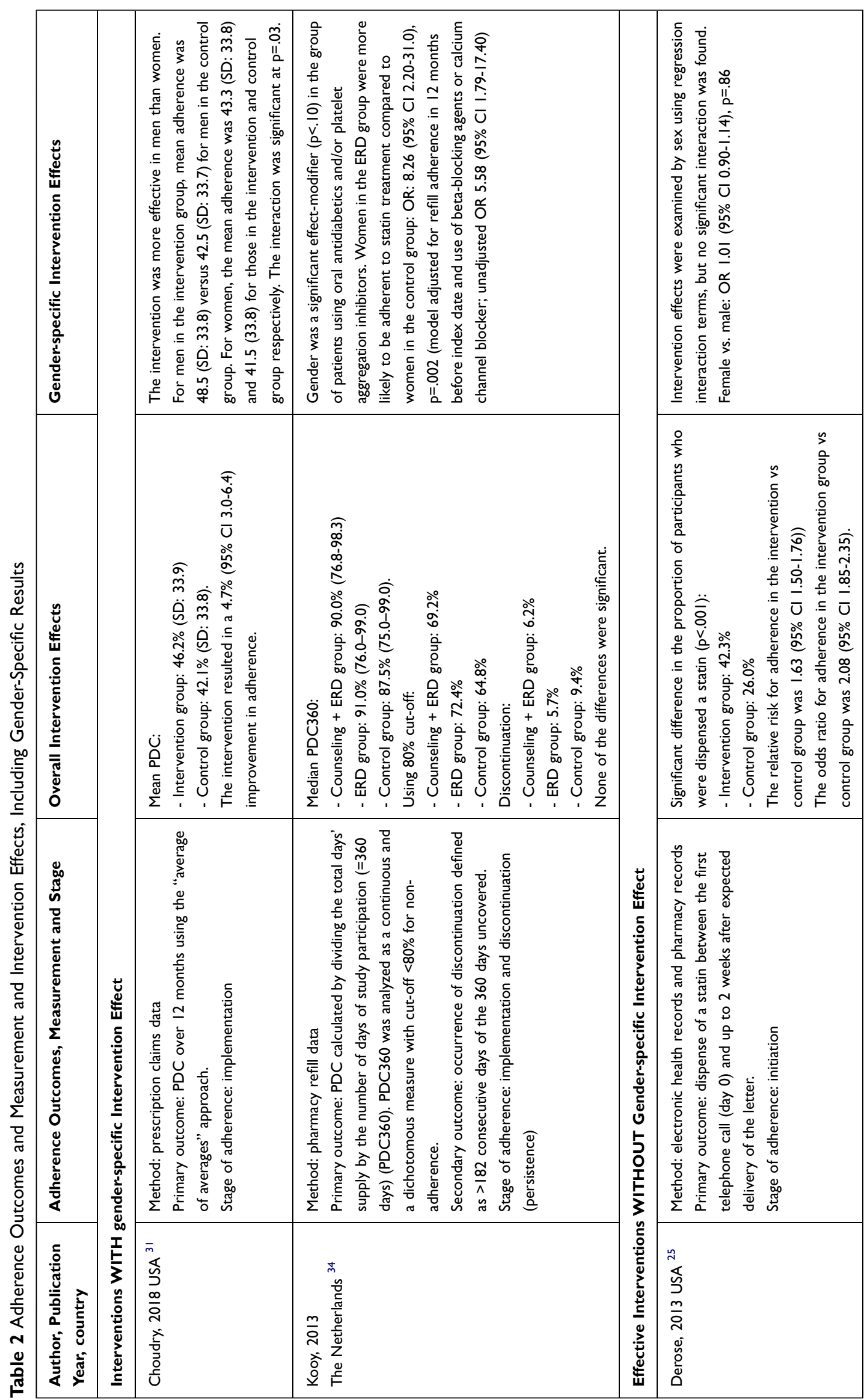




\begin{tabular}{|c|c|c|c|}
\hline 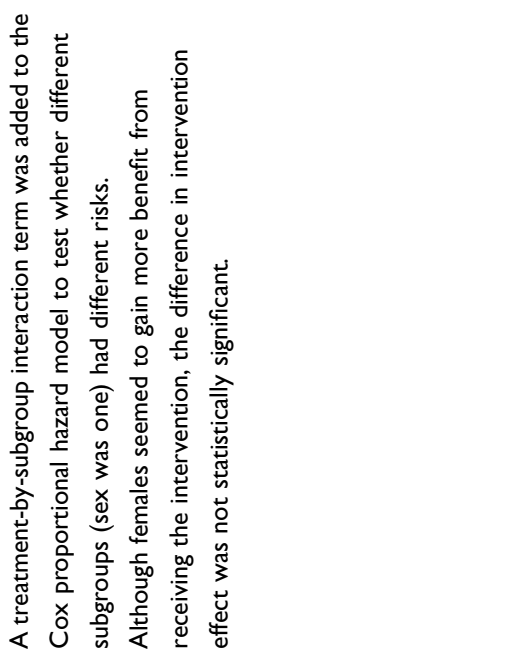 & 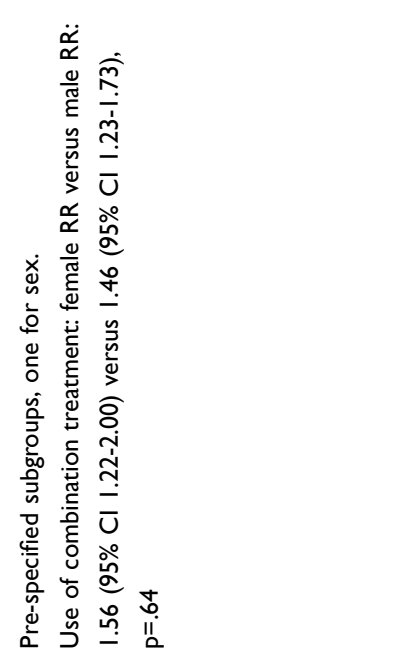 & 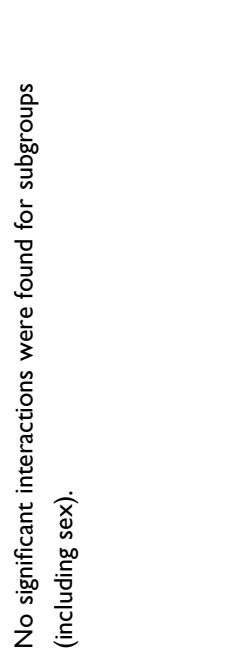 & 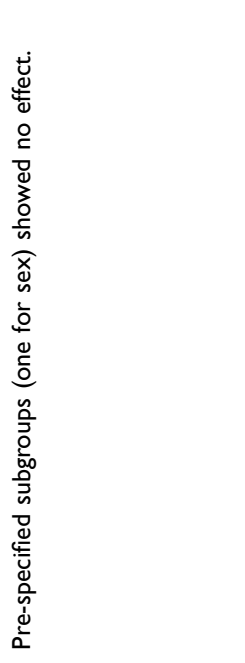 \\
\hline 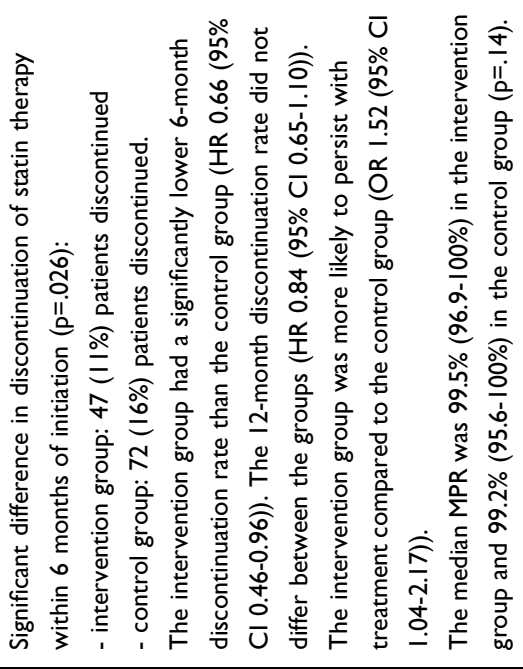 & 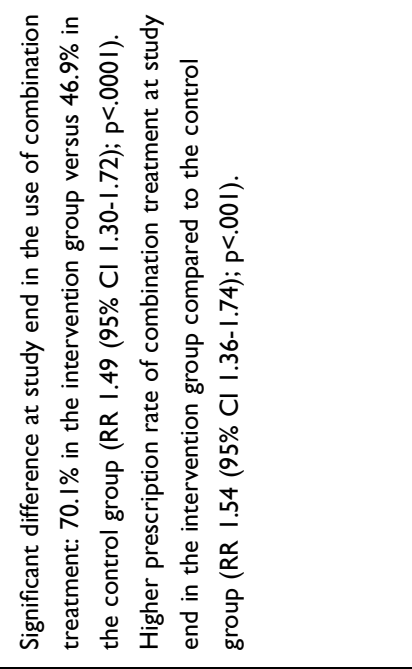 & 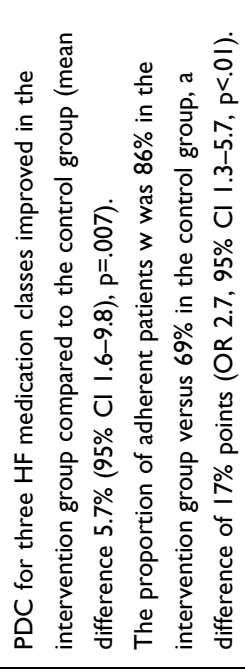 & 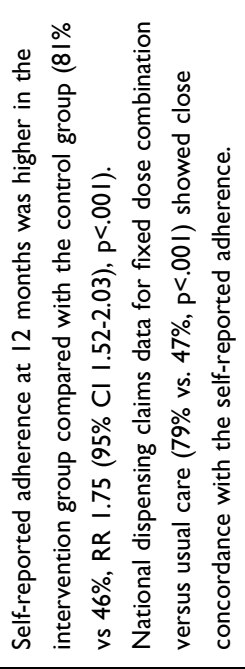 \\
\hline 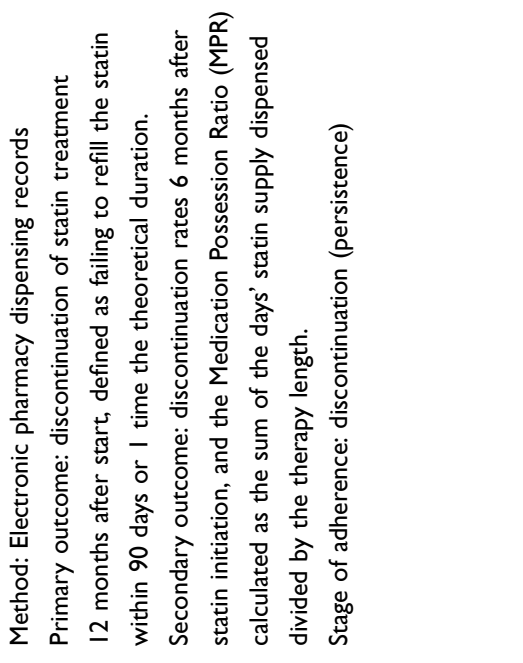 & 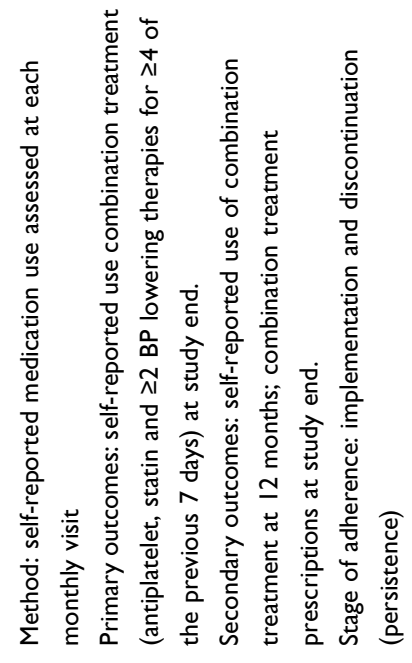 & 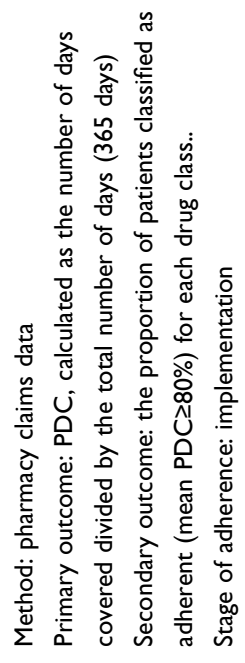 & 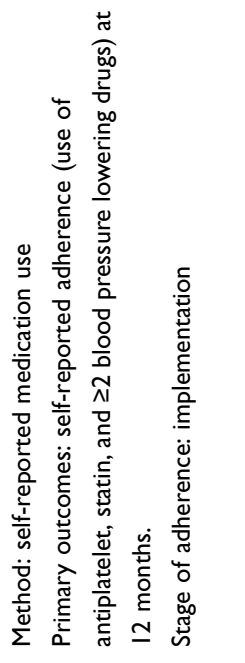 \\
\hline 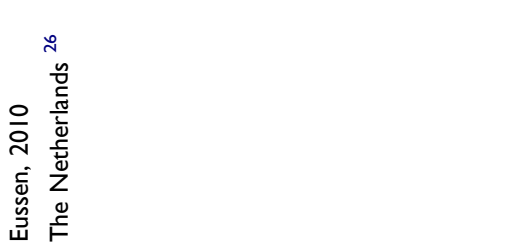 & 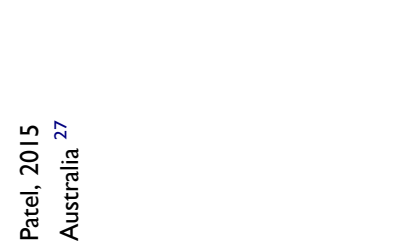 & 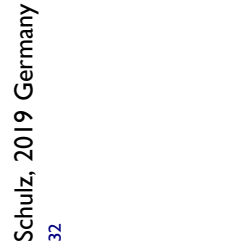 & 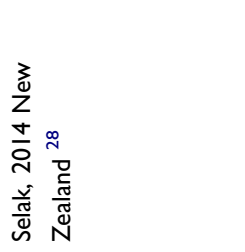 \\
\hline
\end{tabular}




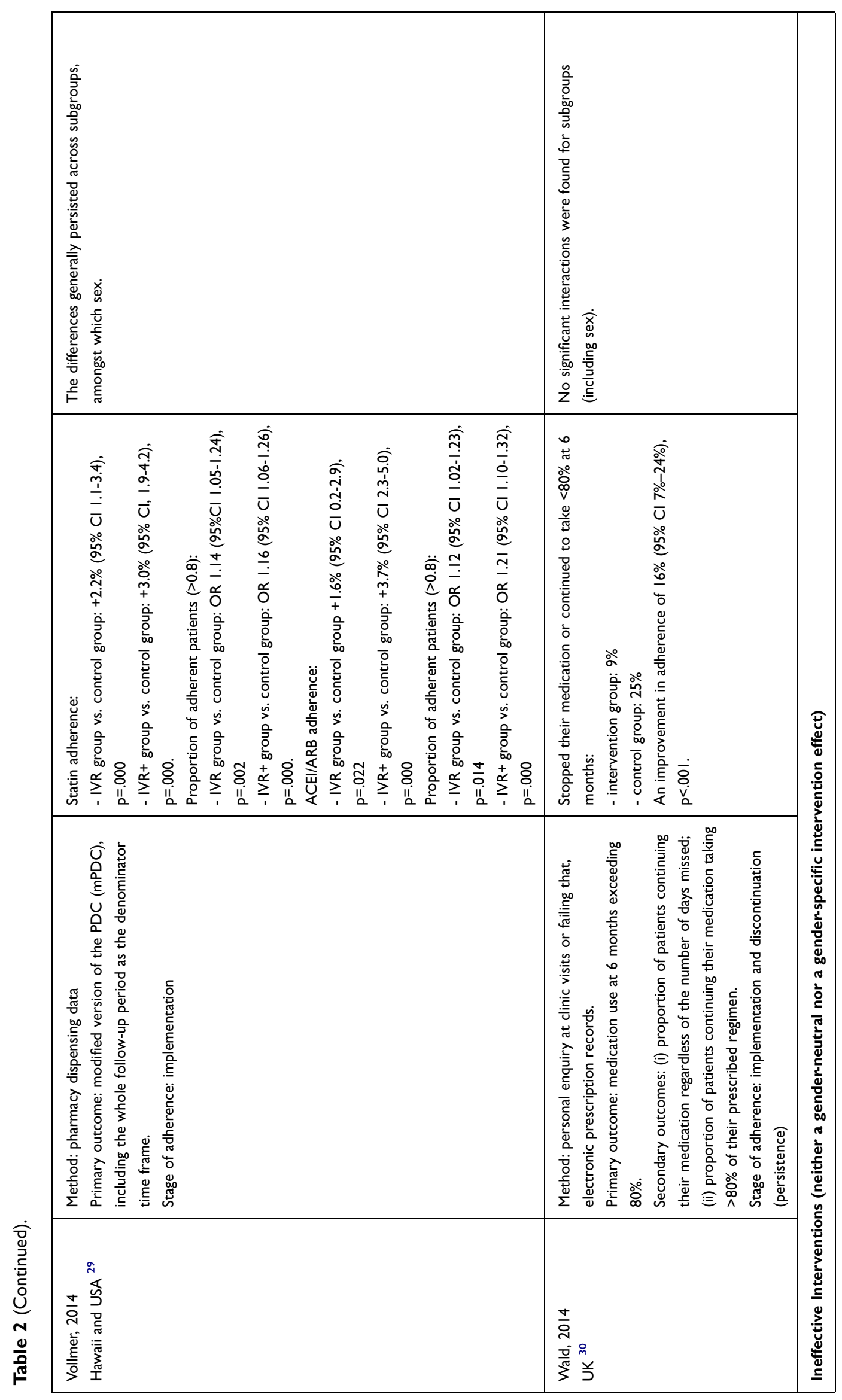




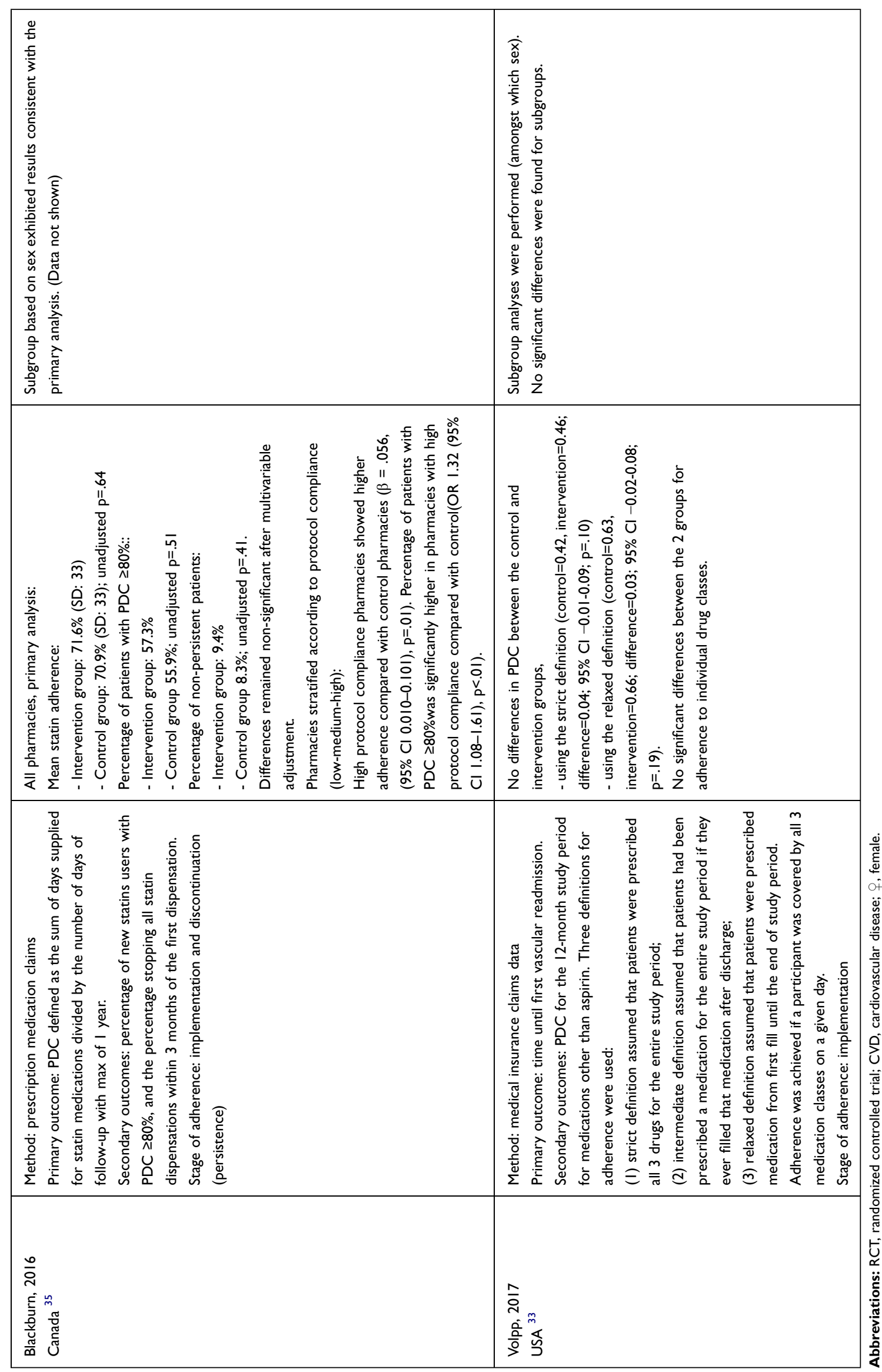


monitoring device, financial incentives, and social support did not improve adherence to medications prescribed after acute myocardial infarction. ${ }^{36}$ In the other study, pharmacists' counseling of new statin users and a follow-up plan tailored to the patient's situation did not lead to improved adherence, nor to more patients achieving optimal adherence $(>80 \%)$, nor to decreased non-persistence. ${ }^{35}$

Seven studies found an overall intervention effect but no gender-specific effect (ie, the effect was similar for men and women). Similar to Kooy et al, two of these seven studies aimed at improving adherence to statin therapy and one of the two also intervened with counseling by the pharmacist. In that study, they had developed a pharmaceutical care program, in which patients starting statin therapy received a $10-15$ minute counseling in the pharmacy during five consecutive visits over a 1-year period. ${ }^{26}$ No differences in refill adherence were found between groups, however, they did find a lower discontinuation rate in the intervention group within six months after starting statin therapy, but this effect diminished after 12 months. Additionally, they found a (non-significant) trend for women gaining more benefit from the counseling visits than men. The second study used automated telephone calls followed by letters to decrease primary non-adherence to statins. Significantly more patients in the intervention group collected their statin medication compared to the control group. ${ }^{25}$

Another two studies were part of a series of international trials promoting a poly-pill strategy to improve adherence to CVD preventive medication, one in Australia ${ }^{27}$ and the other in New Zealand. ${ }^{28}$ Both studies found higher adherence to the poly-pill treatment compared to separate medicines.

The fifth study used interactive voice recognition (IVR) calls with or without additional reminder letters, live outreach and extra materials to improve refill adherence to statins and/or angiotensin-converting enzyme inhibitors/angiotensin receptor blockers (ACEI/ARB). ${ }^{29}$ They found that the intervention groups had significantly higher adherence to both statins and ACEI/ARBs than the control group. In the sixth study, patients who received text messages to remind them of their blood pressure and/or lipidlowering medication intake had a higher adherence than patients receiving no text messages. ${ }^{30}$ In the seventh study, a community pharmacist performed a medication review after which a medication plan was drafted. Patients received a weekly dosing aid and visited the pharmacy (bi-)weekly to update their medication plan (if needed), receive new supplies, be counseled on their medication and adherence. ${ }^{32}$ This intervention led to a significantly improved adherence to three types of heart failure medication compared to the control group.

\section{Risk of Bias Individual Studies}

All but two studies were of high quality, judged by a low risk of bias on five or more domains (Table 3). Concealment of allocation (selection bias) was rated as an unclear risk for most studies, since the method of concealment often was not described or in insufficient detail. For adherence studies, blinding of personnel or participants (performance bias) is often not possible, resulting in a high risk of bias for all studies.

\section{Discussion}

Observational studies show that adherence to cardiovascular medications, especially statins, is on average lower in women compared to men, and that women have different contributing experiences with and beliefs about medication compared to men. ${ }^{4,11,12,20,21}$ Also, women have been found to be more in favor of lifestyle changes over pharmaceutical treatment compared to men. ${ }^{37}$ These findings may support genderspecific approaches to promote adherence, which is the reason why we searched the literature for gender-specific adherence-promoting interventions. However, we did not discover any interventions that addressed gender differences in the development and implementation of the intervention. Only 11 interventions out of $99(11 \%)$ were included in this review as they analyzed differences in intervention effect between men and women. This is in line with a previous review on gender differences in statin use, where the authors concluded that even when enough women were included, gender-specific analyses were rarely conducted, ${ }^{4}$ let alone in studies that powered their study on the main outcome for the whole population rather than subgroup effects. We did find two studies that showed a gender-specific intervention effect, one specifically for women using an electronic reminder device for their statins and one specifically for men after telephone counseling by the pharmacist followed by tailored adherence strategies. However, from these two studies, no general conclusions can be drawn to what type of intervention is more beneficial for men or women.

Differences in adherence levels, beliefs and experiences between men and women have not only been found for CVD but also for diseases such as $\mathrm{HIV}^{38}$ asthma, ${ }^{39}$ cancer, ${ }^{40}$ bipolar disorder, ${ }^{41}$ depression, ${ }^{42}$ and $\mathrm{AHDH} .{ }^{43}$ The nature of these gender differences might 
Table 3 Risk of Bias of Included Studies Determined with the Cochrane Collaboration Tool for Assessing Risk of Bias. Seven Domains of Bias Were Scored Low (Green Dot), High (Red Dot) or Unclear Risk (Yellow Dot)

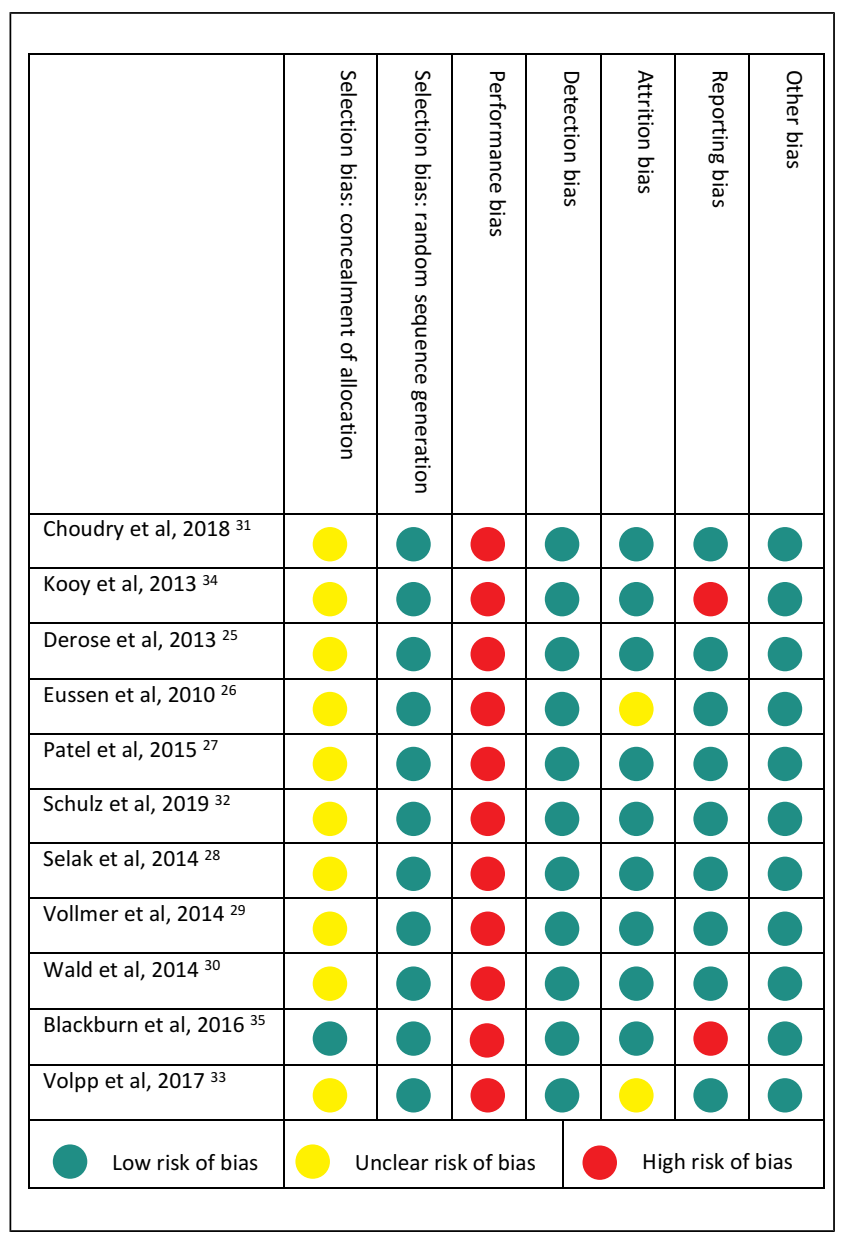

vary across diseases. For example, in a study among patients with cancer, it was found that men had more concerns about their medication (eg, fear for side effects, concerns about long-term effects of the medication) than women. ${ }^{40}$ However, Emilsson et al (2011) showed that among patients with asthma, beliefs about medicines did not differ between men and women. ${ }^{39}$ They did find that the personality trait "neuroticism" (ie, a tendency toward anxiety, depression, self-doubt, and other negative feelings) in men was associated with lower medication adherence whereas in women neuroticism did not have an impact. These findings show that there is ground for interventions that are tailored differently for men and women. This probably also holds for the field of CVD, even though only two intervention studies in this review found different effects for men and women ${ }^{32,34}$ and one other study reported a trend. ${ }^{26}$ These interventions were performed in the pharmacy setting and included patients who were nonadherent at baseline. Targeting only non-adherent patients have been found to be associated with effectiveness of an intervention. ${ }^{44}$ Yet, the interventions were not specifically targeted at unraveling differences between men and women and as such not powered for gender-specific analyses. The same holds for the interventions in this review that did not find gender-specific effects.

Most interventions in this review were general in their approach, not targeting individuals' own specific barriers to adhere to medication. Over the last decade, there is trend towards more personalized approaches to tackle non-adherence as there are many reasons for non-adherence, which also vary widely across patients. ${ }^{44} 46$ Interventions should be tailored to address specific reasons that a patient is nonadherent. As Alleman et al (2018) stated,

In order to obtain clinical benefits from effective adherence interventions, we encourage adherence researchers to select non-adherent patients, measure individual determinants at baseline in a systematic manner, and select and tailor interventions based on the (most important) modifiable determinants in the study population, also in a systematic manner. (p. 77) ${ }^{44}$

These individual determinants may differ between men and women.

\section{Limitations of the Review and Included Studies}

We used a top-down search method and relied on existing databases and its search terms. This approach has the possibility of missing important articles as search terms may be miscoded. A bottom-up strategy is more time consuming but would have been more comprehensive. Still, we assert that only a minor number of intervention studies explicitly addressing gender differences in promoting adherence to cardiovascular medication would have been found. Often, researchers only statistically control for gender or sex effects, ${ }^{4}$ implying that thinking about potentially interesting differences between men and women is not part of the study. The same holds for ensuring that the study is powered to capture differences between men and women. Because of the fact that many studies only controlled for gender or sex effects, it remains unclear how many studies did not report results for men and women separately because there were just no significant differences.

Out of eleven studies analyzing gender differences in intervention effects, only two found an effect specifically for 
either women or men. The remaining nine studies might have been hindered by limited power to detect gender-specific effects $\left(\mathrm{eg},{ }^{30}\right)$ or by lack of fine-tuning the intervention to gender-specific needs. It should be noted that the studies include gender as a male/female dichotomy rather than exploring psychosocial differences and behavioral responses related to gender orientation. This is noteworthy as differences in medication adherence may be more likely to be attributed to psychological rather than of biological mechanisms. Moreover, mechanisms that might explain adherence differences between men and women could be further explored such as differences in health literacy, information seeking behavior and communication with health-care professionals. Another limitation is that we only included three major groups of cardiovascular medication (antihypertensives, lipid lower meds, anticoagulants). As such our results are not representative for all cardiovascular medicines. Finally, we focused on studies published in English or Dutch that were conducted in high-income countries. As a result, our results may not be applicable to low- and middle-income countries.

\section{Clinical and Research Implications}

Our study shows that the influence of gender in promoting adherence to cardiovascular medication is neglected while observational studies show that men and women do differ in levels of and reasons for non-adherence. ${ }^{4,11,12,20}$ It thus is worthwhile to test whether interventions have genderspecific effects. Researchers should not only include gender as a control variable but actually operationalize gender effects, and analyze gender effects accordingly, including ensuring the sample size has sufficient power. For healthcare professionals, it is important to realize that men and women differ in reasons to adhere to medication and, as a consequence, men and women may differ in their reaction to adherence supporting activities. Overall, more awareness is needed for the role of gender in medication adherence promotion. This not only holds for the field of cardiovascular disease but also for other fields.

\section{Conclusion}

Adherence-promoting interventions tackling gender-specific differences are lacking while observational studies have shown that men and women differ in levels and reasons for non-adherence to cardiovascular medication. Increasing awareness about these gender differences might lead to better tailoring of interventions to gender-specific needs, which in turn might lead to better results in improving adherence to cardiovascular medication.

\section{Acknowledgments}

The authors would like to thank Linda Schoonmade (medical librarian) for her support with composing the search strategy and for performing the searches in different electronic databases.

\section{Disclosure}

Dr Marcia Vervloet reports grants from the Netherlands Heart Foundation, during the conduct of the study; grants from AbbVie and Pfizer, outside the submitted work. Dr Joke Korevaar and Dr Chantal Leemrijse report grants from the Netherlands Heart Foundation, during the conduct of the study. Dr. John Paget reports grants from Foundation for Influenza Epidemiology, grants from World Health Organization, grants from Sanofi Pasteur, outside the submitted work. Dr Leah Zullig reports grants from Proteus Digital Health, grants from the PhRMA Foundation, consulting for Novartis, outside the submitted work. Professor Liset van Dijk reports grants from the Netherlands Heart Foundation, during the conduct of the study; grants from Abbvie, grants from Pfizer, outside the submitted work. The authors report no other potential conflicts of interest for this work.

\section{References}

1. WHO. Available from: https://www.who.int/health-topics/cardiovascu lar-diseases\#tab=tab_1. Accessed 21 April, 2020.

2. Patnode CD, Evans CV, Senger CA, Redmond N, Lin JS. Behavioral Counseling to Promote a Healthful Diet and Physical Activity for Cardiovascular Disease Prevention in Adults Without Known Cardiovascular Disease Risk Factors: Updated Systematic Review for the U.S. Preventive Services Task Force. Rockville MD; 2017.

3. Fleming P, Godwin M. Lifestyle interventions in primary care: systematic review of randomized controlled trials. Can Fam Physician. 2008;54(12):1706-1713.

4. Goldstein KM, Zullig LL, Bastian LA, Bosworth HB. Statin Adherence: does Gender Matter? Current Atherosclerosis Reports. 2016;18(11):63. doi:10.1007/s11883-016-0619-9

5. Saeed A, Kampangkaew J, Nambi V. Prevention of Cardiovascular Disease in Women. Methodist Debakey Cardiovasc J. 2017;13(4):185-192.

6. Virani SS, Woodard LD, Ramsey DJ, et al. Gender disparities in evidence-based statin therapy in patients with cardiovascular disease. The American Journal of Cardiology. 2015;115(1):21-26. doi:10.10 16/j.amjcard.2014.09.041

7. Ballo P, Balzi D, Barchielli A, Turco L, Franconi F, Zuppiroli A. Gender differences in statin prescription rates, adequacy of dosing, and association of statin therapy with outcome after heart failure hospitalization: a retrospective analysis in a community setting. European Journal of Clinical Pharmacology. 2016;72(3):311-319. doi:10.1007/s00228-015-1980-2

8. Leifheit-Limson EC, D'Onofrio G, Daneshvar M, et al. Sex Differences in Cardiac Risk Factors, Perceived Risk, and Health Care Provider Discussion of Risk and Risk Modification Among Young Patients With Acute Myocardial Infarction: the VIRGO Study. Journal of the American College of Cardiology. 2015;66 (18):1949-1957. doi:10.1016/j.jacc.2015.08.859 
9. Ljungman C, Kahan T, Schioler L, et al. Antihypertensive treatment and control according to gender, education, country of birth and psychiatric disorder: the Swedish Primary Care Cardiovascular Database (SPCCD). Journal of Human Hypertension. 2015;29 (6):385-393. doi:10.1038/jhh.2014.100

10. Manteuffel M, Williams S, Chen W, Verbrugge RR, Pittman DG, Steinkellner A. Influence of patient sex and gender on medication use, adherence, and prescribing alignment with guidelines. Journal of Women's Health (2002). 2014;23(2):112-119. doi:10.1089/jwh.2012.3972

11. Franconi F, Campesi I. Sex and gender influences on pharmacological response: an overview. Expert Review of Clinical Pharmacology. 2014;7(4):469-485. doi:10.1586/17512433.2014.922866

12. Chen SL, Lee WL, Liang T, Liao IC. Factors associated with gender differences in medication adherence: a longitudinal study. $J$ Adv Nurs. 2014;70(9):2031-2040. doi:10.1111/jan.12361

13. Vrijens B, De Geest S, Hughes DA, et al. A new taxonomy for describing and defining adherence to medications. British Journal of Clinical Pharmacology. 2012;73(5):691-705. doi:10.1111/j.13652125.2012.04167.x

14. Ek S. Gender differences in health information behaviour: a Finnish population-based survey. Health Promotion International. 2015;30 (3):736-745. doi:10.1093/heapro/dat063

15. Dawson KA, Schneider MA, Fletcher PC, Bryden PJ. Examining gender differences in the health behaviors of Canadian university students. The Journal of the Royal Society for the Promotion of Health. 2007;127(1):38-44. doi:10.1177/1466424007073205

16. Lewey J, Shrank WH, Bowry AD, Kilabuk E, Brennan TA, Choudhry NK. Gender and racial disparities in adherence to statin therapy: a meta-analysis. Am Heart J. 2013;165(5):665-678. doi:10.1016/j. ahj.2013.02.011

17. Ingersgaard MVHAT, Norgaard O, Grabowski D, Olesen K, Olesen K. Reasons for Nonadherence to Statins - A Systematic Review of Reviews. Patient Prefer Adherence. 2020;14:675-691. doi:10.2147/ PPA.S245365

18. Ofori-Asenso R, Jakhu A, Curtis AJ, et al. A Systematic Review and Meta-analysis of the Factors Associated With Nonadherence and Discontinuation of Statins Among People Aged $\geq 65$ Years. J Gerontol a Biol Sci Med Sci. 2018;73(6):798-805. doi:10.1093/gerona/glx 256

19. Holmes HM, Luo R, Hanlon JT, Elting LS, Suarez-Almazor M, Goodwin JS. Ethnic disparities in adherence to antihypertensive medications of medicare part D beneficiaries. J Am Geriatr Soc. 2012;60(7):1298-1303. doi:10.1111/j.1532-5415.2012.04037.x

20. Holt E, Joyce C, Dornelles A, et al. Sex differences in barriers to antihypertensive medication adherence: findings from the cohort study of medication adherence among older adults. $J$ Am Geriatr Soc. 2013;61(4):558-564. doi:10.1111/jgs.12171

21. Karalis DG, Wild RA, Maki KC, et al. Gender differences in side effects and attitudes regarding statin use in the Understanding Statin Use in America and Gaps in Patient Education (USAGE) study. $J$ Clin Lipidol. 2016;10(4):833-841. doi:10.1016/j.jacl.2016.02.016

22. Billimek J, Malik S, Sorkin DH, et al. Understanding disparities in lipid management among patients with type 2 diabetes: gender differences in medication nonadherence after treatment intensification. Women's Health Issues: Official Publication of the Jacobs Institute of Women's Health. 2015;25(1):6-12. doi:10.1016/j.whi.2014.09.004

23. Moher D, Liberati A, Tetzlaff J, Altman DG. Preferred reporting items for systematic reviews and meta-analyses: the PRISMA statement. PLoS Medicine. 2009;6(7):e1000097. doi:10.1371/journal. pmed.1000097

24. De Geest S, Zullig LL, Dunbar-Jacob J, et al. ESPACOMP Medication Adherence Reporting Guideline (EMERGE). Ann Intern Med. 2018;169(1):30-35. doi:10.7326/M18-0543

25. Derose SF, Green K, Marrett E, et al. Automated outreach to increase primary adherence to cholesterol-lowering medications. JAMA Intern Med. 2013;173(1):38-43. doi:10.1001/2013.jamainternmed.717
26. Eussen SR, van der Elst ME, Klungel OH, et al. A pharmaceutical care program to improve adherence to statin therapy: a randomized controlled trial. The Annals of Pharmacotherapy. 2010;44(12):19051913. doi:10.1345/aph.1P281

27. Patel A, Cass A, Peiris D, et al. A pragmatic randomized trial of a polypill-based strategy to improve use of indicated preventive treatments in people at high cardiovascular disease risk. European Journal of Preventive Cardiology. 2015;22(7):920-930. doi:10.11 77/2047487314530382

28. Selak V, Elley CR, Bullen C, et al. Effect of fixed dose combination treatment on adherence and risk factor control among patients at high risk of cardiovascular disease: randomised controlled trial in primary care. BMJ (Clinical Research Ed. 2014;348:g3318.

29. Vollmer WM, Owen-Smith AA, Tom JO, et al. Improving adherence to cardiovascular disease medications with information technology. The American Journal of Managed Care. 2014;20(11 Spec No. 17):502-510.

30. Wald DS, Bestwick JP, Raiman L, Brendell R, Wald NJ. Randomised trial of text messaging on adherence to cardiovascular preventive treatment (INTERACT trial). PLoS One. 2014;9(12):e114268. doi:10.1371/journal.pone.0114268

31. Choudhry NK, Isaac T, Lauffenburger JC, et al. Effect of a Remotely Delivered Tailored Multicomponent Approach to Enhance Medication Taking for Patients With Hyperlipidemia, Hypertension, and Diabetes: the STIC2IT Cluster Randomized Clinical Trial. JAMA Intern Med. 2018;178(9):1182-1189. doi:10.1001/jamainternmed.20 18.3189

32. Schulz M, Griese-Mammen N, Anker SD, et al. Pharmacy-based interdisciplinary intervention for patients with chronic heart failure: results of the PHARM-CHF randomized controlled trial. Eur J Heart Fail. 2019;21(8):1012-1021. doi:10.1002/ejhf.1503

33. Volpp KG, Troxel AB, Mehta SJ, et al. Effect of Electronic Reminders, Financial Incentives, and Social Support on Outcomes After Myocardial Infarction: the HeartStrong Randomized Clinical Trial. JAMA Intern Med. 2017;177(8):1093-1101. doi:10.1001/ jamainternmed.2017.2449

34. Kooy MJ, van Wijk BL, Heerdink ER, de Boer A, Bouvy ML. Does the use of an electronic reminder device with or without counseling improve adherence to lipid-lowering treatment? The results of a randomized controlled trial. Frontiers in Pharmacology. 2013;4:69. doi:10.3389/fphar.2013.00069

35. Blackburn DF, Evans CD, Eurich DT, et al. Community Pharmacists Assisting in Total Cardiovascular Health (CPATCH): A ClusterRandomized, Controlled Trial Testing a Focused Adherence Strategy Involving Community Pharmacies. Pharmacotherapy. 2016;36(10):1055-1064. doi:10.1002/phar.1831

36. Reddy A, Huseman TL, Canamucio A, et al. Patient and Partner Feedback Reports to Improve Statin Medication Adherence: A Randomized Control Trial. J Gen Intern Med. 2017;32(3):256-261. doi:10.1007/s11606-016-3858-0

37. Jarbol DE, Larsen PV, Gyrd-Hansen D, et al. Determinants of preferences for lifestyle changes versus medication and beliefs in ability to maintain lifestyle changes. A population-based survey. Preventive Medicine Reports. 2017;6:66-73. doi:10.1016/j.pmedr.2017.02.010

38. Puskas CM, Forrest JI, Parashar S, et al. Women and vulnerability to HAART non-adherence: a literature review of treatment adherence by gender from 2000 to 2011. Current HIV/AIDS Reports. 2011;8 (4):277-287. doi:10.1007/s11904-011-0098-0

39. Emilsson M, Berndtsson I, Lotvall J, et al. The influence of personality traits and beliefs about medicines on adherence to asthma treatment. Primary Care Respiratory Journal: Journal of the General Practice Airways Group. 2011;20(2):141-147. doi:10.4104/ pcrj.2011.00005

40. Sikorskii A, Given CW, Given BA, et al. Do treatment patterns alter beliefs cancer patients hold regarding oral oncolytic agents? PsychoOncology. 2018;27(3):1005-1012. doi:10.1002/pon.4606 
41. Sajatovic M, Micula-Gondek W, Tatsuoka C, Bialko C. The relationship of gender and gender identity to treatment adherence among individuals with bipolar disorder. Gender Medicine. 2011;8(4):261268. doi:10.1016/j.genm.2011.06.002

42. Gerlach LB, Kavanagh J, Watkins D, Chiang C, Kim HM, Kales HC. With a little help from my friends?: racial and gender differences in the role of social support in later-life depression medication adherence. International Psychogeriatrics. 2017;29(9):1485-1493. doi:10.1017/S104161021700076X

43. Emilsson M, Gustafsson PA, Ohnstrom G, Marteinsdottir I. Beliefs regarding medication and side effects influence treatment adherence in adolescents with attention deficit hyperactivity disorder. European Child \& Adolescent Psychiatry. 2017;26(5):559-571. doi:10.1007/ s00787-016-0919-1
44. Allemann SS, Nieuwlaat R, Navarro T, Haynes B, Hersberger KE, Arnet I. Congruence between patient characteristics and interventions may partly explain medication adherence intervention effectiveness: an analysis of 190 randomized controlled trials from a Cochrane systematic review. J Clin Epidemiol. 2017;91:70-79. doi:10.1016/j. jclinepi.2017.07.011

45. Hugtenburg JG, Timmers L, Elders PJ, Vervloet M, van Dijk L. Definitions, variants, and causes of nonadherence with medication: a challenge for tailored interventions. Patient Prefer Adherence. 2013;7:675-682. doi:10.2147/PPA.S29549

46. Nieuwlaat R, Wilczynski N, Navarro $\mathrm{T}$, et al. Interventions for enhancing medication adherence. The Cochrane Database of Systematic Reviews. 2014;11:Cd000011.

\section{Publish your work in this journal}

Patient Preference and Adherence is an international, peer-reviewed, open access journal that focusing on the growing importance of patient preference and adherence throughout the therapeutic continuum. Patient satisfaction, acceptability, quality of life, compliance, persistence and their role in developing new therapeutic modalities and compounds to optimize clinical outcomes for existing disease states are major areas of interest for the journal. This journal has been accepted for indexing on PubMed Central. The manuscript management system is completely online and includes a very quick and fair peer-review system, which is all easy to use. Visit http:// www.dovepress.com/testimonials.php to read real quotes from published authors. 